\title{
Inhibition of L-NAME-Induced Hypertension by Combined Treatment With Apocynin and Catalase: The Role of Nox 4 Expression
}

\author{
Tan Yong CHIA ${ }^{1}$, Vikneswaran MURUGAIYAH ${ }^{2}$, Nurzalina Abdul Karim KHAN ${ }^{3}$, \\ Munavvar Abdul SATTAR ${ }^{1}$, Mohammed Hadi ABDULLA ${ }^{4}$, Edward James JOHNS ${ }^{4}$, Ashfaq \\ AHMAD $^{5}$, Zurina HASSAN ${ }^{6}$, Gurjeet KAUR ${ }^{7}$, Ho Yoke MEI ${ }^{3}$, Fiaz Uddin AHMAD ${ }^{8}$, Safia \\ AKHTAR $^{9}$
}

${ }^{1}$ Cardiovascular and Renal Physiology Research Laboratory, School of Pharmaceutical Sciences, Universiti Sains Malaysia, Minden, Penang, Malaysia, ${ }^{2}$ Department of Pharmacology, School of Pharmaceutical Sciences, Universiti Sains Malaysia, Minden, Penang, Malaysia, ${ }^{3}$ Department of Pharmaceutical Technology, School of Pharmaceutical Sciences, Universiti Sains Malaysia, Minden, Penang, Malaysia, ${ }^{4}$ Department of Physiology, School of Medicine, University College of Cork, Cork, Ireland, ${ }^{5}$ Department of Pharmacy, Abasyn University Islamabad Campus, Islamabad, Pakistan, ${ }^{6}$ Center of Drug Research, Universiti Sains Malaysia, Minden, Penang, Malaysia, ${ }^{7}$ Institute for Research in Molecular Medicine, Universiti Sains Malaysia, Minden, Penang, Malaysia, ${ }^{8}$ Department of Pharmacy, Islamia University of Bahawalpur, Bahawalpur, Pakistan, ${ }^{9}$ Department of Endocrinology, School of Medicine, University of Virginia, Charlottesville, Virginia, USA

Received May 1, 2020

Accepted August 11, 2020

\section{Summary}

Reactive oxygen species (ROS) such as superoxide $\left(\mathrm{O}_{2}{ }^{-}\right)$generated by $\mathrm{NAD}(\mathrm{P}) \mathrm{H}$ oxidases have emerged as important molecules in blood pressure regulation. This study investigated the effect of apocynin and catalase on blood pressure and renal hemodynamic and excretory function in an L-NAME induced hypertension model. Forty Male Wistar-Kyoto (WKY) rats ( $n=8$ per group) were treated with either: vehicle (WKY-C); L-NAME (WKY-L, $15 \mathrm{mg} / \mathrm{kg} /$ day in drinking fluid); WKY-L given apocynin to block NAD(P)H oxidase (WKY-LApo, $73 \mathrm{mg} / \mathrm{kg} /$ day in drinking water.); WKY-L given catalase to enhance ROS scavenging (WKY-LCat, $10000 \mathrm{U} / \mathrm{kg} /$ day i.p.); and WKY-L receiving apocynin plus catalase (WKY-LApoCat) daily for 14 days. L-NAME elevated systolic blood pressure (SBP), $116 \pm 1$ to $181 \pm 4 \mathrm{~mm} \mathrm{Hg}$, reduced creatinine clearance, $1.69 \pm 0.26$ to $0.97 \pm 0.05 \mathrm{ml} / \mathrm{min} / \mathrm{kg}$ and fractional sodium excretion, $0.84 \pm 0.09$ to $0.55 \pm 0.09 \%$ at day 14 . Concomitantly, plasma malondialdehyde (MDA) increased six fold, while plasma total superoxide dismutase (T-SOD), plasma nitric oxide (NO) and plasma total antioxidant capacity (T-AOC) were decreased by 60-70\% and Nox 4 mRNA expression was increased 2-fold. Treatment with apocynin and catalase attenuated the increase in SBP and improved renal function, enhanced antioxidative stress capacity and reduced the magnitude of Nox 4 mRNAs expression in the L-NAME treated rats. This study demonstrated that apocynin and catalase offset the development of L-NAME induced hypertension, renal dysfunction and reduced oxidative stress status, possibly contributed by a reduction in Nox 4 expression during NOS inhibition. These findings would suggest that antioxidant compounds such as apocynin and catalase have potential in treating cardiovascular diseases.

\section{Key words}

Renal function - Hypertension - Oxidative stress - NAD(P)H oxidase $\bullet$ Reactive oxygen species

\section{Corresponding authors}

T. Y. Chia, Cardiovascular and Renal Physiology Research Laboratory, School of Pharmaceutical Sciences, Universiti Sains Malaysia, Minden, Penang, Malaysia. E-mail: tanyongchia@student.usm.my/samual_84@hotmail.com and V. Murugaiyah, Department of Pharmacology, School of Pharmaceutical Sciences, Universiti Sains Malaysia, Minden, Penang, Malaysia. E-mail: vicky@usm.my 


\section{Introduction}

Evidence from observational studies worldwide have shown strong, positive relationships between hypertension and the risk of cardiovascular complications including heart failure, peripheral vascular disease and renal impairment (World Health Organization 2017). Compelling experimental evidence has indicated that oxidative stress and production of reactive oxygen species (ROS) play a pivotal role in the pathogenesis of hypertension and renal dysfunction (Shokoji et al. 2003). In hypertension, there is a raised production of ROS that has potentially damaging effects on lipids, proteins and DNA, react with nitric oxide (NO) and may, in part, impact on the physiological regulation of intracellular signal transduction (Johns et al. 2010, Chia et al. 2020).

NO is a free radical gas molecule determining the relaxation of vascular smooth muscle cells, hormonal and neurotransmission functions (Ignarro 1999) generated endogenously from L-arginine via the action of the NO synthase (NOS) enzyme (Pechanova et al. 2004). There is evidence that NO acts within the central nervous system to modulate cardiovascular control by mean of a sympathoinhibitory response (Hirai et al. 1995) as NO inhibition activates both global and renal sympathetic activity (Togashi et al. 1992) associated with an increase in arterial BP (Activit 1992). NO levels are diminished in human hypertensive subjects, supporting the notion that derangements of NO levels play a role in hypertension (Brunini et al. 2004).

The Nox 4 enzymes upon activation and translocation to the mitochondrial membrane, transfer electrons from the substrate oxygen $\left(\mathrm{O}_{2}\right)$ to form $\mathrm{O}_{2}{ }^{-}$ (Johns et al. 2010). A number of NAD(P)H homologs have been identified which comprise seven members, Nox 1 to Nox 5, Duox 1 and Duox 2 with Nox 4 being the most highly expressed Nox family member within the cardiovascular system (Guzik et al. 2004) and at high levels in the kidney cortex. Nox 4 is commonly co-expressed with other homologs such as Nox 1 and Nox 2 but at significantly higher levels (Geiszt et al. 2000). Previous studies suggest that up-regulation of the vascular Nox 4 isoform leads to functional and structural alterations in the vascular wall leading to endothelial dysfunction, increased vascular tone, and vascular hypertrophy (Lassegue et al. 2012, Lee et al. 2013). Increased $\mathrm{O}_{2}{ }^{-}$production by up-regulated vascular Nox 4 may diminish the effectiveness of NO and thus contribute to the development of vascular diseases (Nistala et al. 2009).
The potential role of ROS in hypertension became apparent from studies where exogenous administration of superoxide dismutase (SOD) to spontaneously hypertensive rats reduced BP (Chan et al. 2006, Chia et al. 2013). NAD(P)H oxidases were found to be the source of the ROS (Nakazono et al. 1991, Williams and Griendling 2007, Selemidis et al. 2008) and that in hypertensive animals upregulation of NAPDH oxidase subunits led to a blood pressure (BP) increase with vascular remodeling (Lassegue and Griendling 2010, Chia et al. 2013). The synthetic SOD mimetic, tempol, reduced the presence of $\mathrm{O}_{2}^{-}$(Chia et al. 2013) but a heightened $\mathrm{O}_{2}^{-}$dismutation alone in the absence of concomitant increase in catalase activity would result in enhanced production of the oxidant compound $\mathrm{H}_{2} \mathrm{O}_{2}$ (Lee et al. 2013). Collectively, these reports have strengthened the view that increased ROS production and oxidative stress is an inevitable element of hypertension.

The present study explored the impact of hypertension resulting from NOS inhibition with $\mathrm{N} \omega$-Nitro-L-arginine methyl ester hydrochloride (L-NAME) on renal Nox 4 expression in the kidney and its influence on renal functional and histological parameters. This was done using apocynin, to block the activity of the NAD $(\mathrm{P}) \mathrm{H}$ oxidase activity, and catalase to increase scavenging of ROS, both individually and together to determine the contribution of these oxidant entities.

\section{Methods}

\section{Experimental animals}

Forty male Wistar-Kyoto (WKY) rats $(200 \pm 10 \mathrm{~g})$ were obtained from the Animal Research Unit and Service Center (ARASC) of Universiti Sains Malaysia, Penang. All animals were housed in the same environmental conditions (12:12 h light-dark cycle; temperature, $24{ }^{\circ} \mathrm{C}$; humidity, 60-70\%) with free access to rat chow (Gold Coin, Sdn. Bhd., Penang, Malaysia) and tap water ad libitum. Animals were subjected to 5 days of acclimatization prior to the start of any experiment. All experimental procedures were performed under the approval and guidelines under the USM Institutional Animal Care and Use Committee with approval letter Code USM/IACUC/2017/ (106) (844).

\section{Treatment protocols}

Animals were randomly divided into five groups $(n=8)$, namely: WKY control rats (WKY-C) which did not receive any treatment; WKY rats treated with 
L-NAME (Sigma-Aldrich, St. Louis, Missouri, United States) where L-NAME was dissolved in the drinking water at $12.5 \mathrm{mg} / \mathrm{ml}$ and, based on the average volume of fluid intake and animal weight, this equated to approximately $15 \mathrm{mg} / \mathrm{kg} /$ day (WKY-L); L-NAME+apocynin rats were given in drinking water containing both L-NAME, as above, together with $2.5 \mathrm{mmol} / \mathrm{l}$ apocynin, which resulted in an average intake of apocynin of $73 \mathrm{mg} / \mathrm{kg} /$ day (WKY-LApo); WKY-L rats treated with catalase (Sigma-Aldrich, St. Louis, Missouri, United States) at a dose of $10000 \mathrm{U} / \mathrm{kg} / \mathrm{day}$ i.p. (WKY-LCat); WKY-L treated with a combination of apocynin plus catalase (WKY-LApoCat) respectively. All animals were subjected to these regimes for 14 days.

\section{Metabolic and renal functional studies}

Weekly metabolic data were monitored starting from day 0 where animals were housed in individual metabolic cages (Nalgene $\AA$, Thermo Scientific, Philadelphia, USA) for 24-h for water intake and urine collection. Body weight was monitored on day 0 , day 7 and day 14 respectively. 24-h urine samples and tail-vein blood samples were obtained and centrifuged at $3500 \mathrm{rpm}$ for $10 \mathrm{~min}$ before removal of plasma and storage at $-30{ }^{\circ} \mathrm{C}$ until further biochemical analysis.

\section{Plasma and urine biochemistry}

Weekly plasma and urine samples were collected for the measurement of creatinine and sodium in urine. Plasma and urine creatinine analysis was performed using Jaffe's reaction method whereas, urinary protein levels were measured spectrophotometrically using Bradford's assay method (Power Wave X340, Bio.Tek Instrument Inc., USA), while sodium and potassium levels were measured with a flame photometer (Jenway, PFP-7, England, UK). Creatinine clearance $(\mathrm{CrCl})$, fractional sodium excretion $\left(\mathrm{FE}_{\mathrm{Na}}{ }^{+}\right)$and urinary protein excretion (UPE) were calculated using standard equations as previously reported (Chia 2013, Tan et al. 2020).

\section{Measurement of blood pressure non-invasively}

Weekly systolic blood pressure (SBP) was measured using CODA ${ }^{\circledR}$ tail cuff plethysmography (Kent Scientific Corporation, Torrington, CT, USA). Rats were trained to accept the recording environment before going on to establish the basal SBP before starting the experimental protocols. Special care was taken to minimize the stress induced by external environment on the animals by locating the restrainer on a heater panel provided by the $\operatorname{CODA}{ }^{\circledR}$ tail cuff plethysmography system (Kent Scientific Corporation, Torrington, CT, USA). Over each measurement period a total of 10 consecutive readings were selected for each rat and an average SBP value was calculated.

\section{Hemodynamic study}

General preparation and surgical procedures

At the end of the experiment, animals were subjected to an acute renal hemodynamic protocol. In order to avoid possible involvement of the effect of acute drug administration, all procedures were conducted within the 24-h post-treatment period. Rats were fasted overnight, with continued access to their drinking water, and anesthetized with $60 \mathrm{mg} / \mathrm{kg}$ of sodium pentobarbitone (Nembutal®), CEVA, Santé Animale, Libourne, France). A supplementary catheter was inserted into the left jugular vein to allow bolus doses of $15 \mathrm{mg} / \mathrm{kg}$ of sodium pentobarbitone (Nembutal ${ }^{\circledR}$, CEVA, Santé Animale, Libourne, France) to be administered to ensure a constant level of anaesthesia. An endotracheal cannula was inserted to maintain a clear airways (PE250, Portex, Kent, UK). The right carotid artery was then cannulated (PE50, Portex, Kent, UK) and inserted to the level of the aortic arch to allow continuous invasive mean arterial blood pressure (MAP) recording (P23 ID Gould, Statham Instruments, London, UK). Another cannula (PE50, Portex, Kent, UK) was introduced into the abdominal aorta through the left iliac artery for the measurement of iliac BP. Following this, a midline incision was performed to expose the left kidney and a laser-Doppler flow probe (OxyFlow, AdInstruments, Sydney, Australia) was positioned on the dorsal surface of the exposed left kidney for the measurement of renal cortical blood perfusion (RCBP) using a laser-Doppler flowmeter (PowerLab ${ }^{\circledR}$, AD Instruments, Sydney, Australia). While running the experiment, the kidney surface was constantly irrigated with normal saline solution to prevent dehydration. The recording system was linked to a data acquisition system (Powerlab ${ }^{\circledR}$, ADinstruments, Colorado Springs, CO, USA) through Quad Amp using chart Pro (V.5.5) software.

\section{Measurement of pulse wave velocity}

The animals were allowed to stabilize for $1 \mathrm{~h}$ upon completion of the surgical procedure. Pulse wave velocity (PWV) was measured as described by (Wang et al. 2000). Briefly, pulse pressure waves from the two pressure transducers were simultaneously recorded and displayed on the data acquisition system. The full length 
of the aorta was exposed and the distance between the tips of the two cannulae measured (d). The propagation time $(\mathrm{t})$ for the BP wave moving from aortic arch to abdominal aorta was measured manually as the time delay between the upstrokes (foot) of each pressure wave front using the "foot to foot" measurement approach. The calculation was done using the following equation: $\mathrm{PWV}=\mathrm{d} / \mathrm{t}$; and the units are expressed in meter per second $(\mathrm{m} / \mathrm{s})$. $\beta$-index was adopted to evaluate the participation of diastolic blood pressure (DBP) in increasing arterial stiffness. It was calculated using the following equation; $\beta$-index $=2.2 \times(\mathrm{PWV})^{2} / \mathrm{DBP}($ Cosson, Herisse et al. 2007).

\section{Measurement of oxidative stress markers}

On termination of the hemodynamic study, $3 \mathrm{ml}$ of arterial blood was withdrawn via the carotid artery and then centrifuged at $3500 \mathrm{rpm}$ for $10 \mathrm{~min}$ for plasma collection. Plasma samples were stored at $-30{ }^{\circ} \mathrm{C}$ until biochemical analysis for oxidative stress markers. Plasma malondialdehyde (MDA), total superoxide dismutase (T-SOD), nitric oxide (NO) as total nitrite/nitrate and total antioxidant capacity (T-AOC) were measured using the spectrophotometric detection kits (Nanjing Jiancheng, Bioengineering Institute, China). All the measurements were performed according to the manufacturer's instructions.

\section{Histology study and kidney index}

Upon the completion of the acute studies, animals were euthanized with an overdose of anesthetic (Nembutal $^{\circledR}$, Ceva, Santé Animale, Libourne, France) and disposed via the animal carcass collection facility located in the ARASC of Universiti Sains Penang, Malaysia. The contralateral kidney was carefully isolated from the circumferential adipose and connective tissues. The left kidney was then blotted dry on a piece of laboratory filter paper and fixed with $10 \%$ neutral buffered formalin solution until histological examination. Both kidney weights were summed and used for the estimation of kidney index using the following standard equation: kidney weight/body weight $\times 100$ (Chia 2013, Tan et al. 2020).

\section{Molecular expression of renal Nox $4 \mathrm{mRNAs}$}

The quantification of mRNA was undertaken using real time polymerase chain reactions (RT-PCR) and performed using the right kidney from all rats. Kidneys were harvested and stored in RNAlater solution (Ambion, Life Technologies, Pleasanton, CA, USA) at $-80^{\circ} \mathrm{C}$ in order to maintain RNA integrity until further processing.
The molecular expression study was performed following the procedure reported previously (Ahmad et al. 2016). TaqMan primers and probes were adopted for genes which have the following accession numbers; Nox 4 gene (GenBank Accession N0. AY027527.1 and Rn00585380_m1) were derived from TaqMan-Gene Expression assays (Applied Biosystems, Waltham, MA, USA) (Kitiyakara et al. 2003, Tan et al. 2020). Similarly, TaqMan primers and probes for the $\beta$-actin gene (endogenous control) (GenBank Accession No. NM_031144.3 and Rn00667869_m1) were also derived from TaqMan-Gene Expression assays (Applied Biosystems, Waltham, MA, USA). The expression assay kits were procured and the procedures performed according to the manufacturer's instructions. Amplification of $\beta$-actin as the housekeeping gene enabled sample loading and normalization to be determined. The relative quantification of the target gene Nox 4 and $\beta$-actin was calculated using the comparative $\mathrm{C}_{\mathrm{T}}$ (threshold cycle) method with arithmetic formula $\left(2^{-\Delta \Delta \mathrm{CT}}\right)$ (Livak and Schmittgen 2001, Kitiyakara et al. 2003, Tan et al. 2020).

\section{Statistical analysis}

Data arising from the metabolic and renal functional parameters were analyzed using repeated measures one-way ANOVA. Other data including oxidative stress markers, hemodynamics and molecular studies were analyzed using one-way ANOVA followed by the Bonferroni posthoc test. All the data were presented as mean \pm S.E.M with significance taken at $\mathrm{P}<0.05$. GraphPad Prism ${ }^{\circledR}$ Version 2.1 software (GraphPad Software, San Diego, California, USA) was used for statistical analysis.

\section{Results}

Effect of apocynin and catalase on body weight and water intake

The basal body weight at the beginning of the treatment period was the same in all rat groups (Table 1). Generally, the body weight over the course of the study significantly $(\mathrm{P}<0.05)$ increased in all the experimental groups from day 7 till the end of the study period except for the WKY-L rats which had a significantly $(\mathrm{P}<0.05)$ slower body weight gain as compared to WKY-C rats (Table 1). The WKY-LApo, WKY-LCat and WKYLApoCat groups of rats had significantly (all $\mathrm{P}<0.05$ ) higher body weights as compared to WKY-L rats on day 14 (Table 1). 
Table 1. Body weight, water intake, systolic blood pressure, heart rate, urine output, creatinine clearance, fractional sodium excretion, urinary sodium to potassium ratio $\left(\mathrm{U}_{\mathrm{Na}}{ }^{+}: \mathrm{U}_{\mathrm{K}}{ }^{+}\right.$ratio), urinary sodium excretion and kidney index over the 14 days study period in control (WKY-C), L-NAME treated (WKY-L), WKY-L treated with apocynin (WKY-LApo), WKY-L treated with catalase (WKY-LCat) and WKY-L treated with apocynin plus catalase (WKY-LApoCat) rats.

\begin{tabular}{|c|c|c|c|c|c|c|c|}
\hline \multirow{2}{*}{ Parameter } & \multirow{2}{*}{ Group } & \multirow{2}{*}{$\mathbf{n}$} & \multicolumn{5}{|c|}{ Day } \\
\hline & & & $\mathbf{0}$ & 7 & & 14 & \\
\hline \multirow{5}{*}{$\begin{array}{l}\text { Body Weight } \\
\text { (g) }\end{array}$} & WKY-C & 8 & $204.7 \pm 1.5$ & $229.4 \pm 3.9$ & $*$ & $251.2 \pm 3.6$ & $*$ \\
\hline & WKY-L & 8 & $204.1 \pm 1.6$ & $220.5 \pm 4.8$ & $*$ & $225.5 \pm 1.0$ & $*$ \\
\hline & WKY-L Apo & 8 & $205.9 \pm 1.1$ & $243.7 \pm 6.1$ & $*$ & $259.9 \pm 7.1$ & $*, \dagger$ \\
\hline & WKY-L Cat & 8 & $207.6 \pm 0.9$ & $241.4 \pm 11.2$ & $*$ & $265.9 \pm 4.2$ & $*, \dagger$ \\
\hline & WKY-L ApoCat & 8 & $208.7 \pm 2.8$ & $236.7 \pm 4.1$ & $*$ & $261.1 \pm 3.6$ & $*, \dagger$ \\
\hline \multirow{5}{*}{$\begin{array}{l}\text { Water intake } \\
(\mathrm{ml} / \mathrm{kg} / \text { day })\end{array}$} & WKY-C & 8 & $7.22 \pm 0.83$ & $7.32 \pm 1.07$ & & $7.54 \pm 1.04$ & \\
\hline & WKY-L & 8 & $7.65 \pm 0.75$ & $6.35 \pm 0.95$ & $*$ & $6.33 \pm 0.82$ & *,\# \\
\hline & WKY-L Apo & 8 & $7.47 \pm 0.61$ & $7.35 \pm 0.76$ & & $7.74 \pm 0.89$ & $\dagger$ \\
\hline & WKY-L Cat & 8 & $7.30 \pm 0.93$ & $7.77 \pm 1.07$ & & $7.60 \pm 1.01$ & $\dagger$ \\
\hline & WKY-L ApoCat & 8 & $7.93 \pm 1.10$ & $8.36 \pm 0.83$ & & $7.87 \pm 1.09$ & $\dagger$ \\
\hline \multirow{5}{*}{$\begin{array}{l}\text { Systolic blood } \\
\text { pressure } \\
\text { (mm Hg) }\end{array}$} & WKY-C & 8 & $115 \pm 1$ & $117 \pm 1$ & & $120 \pm 2$ & \\
\hline & WKY-L & 8 & $116 \pm 1$ & $163 \pm 5$ & $*$ & $181 \pm 4$ & *,\# \\
\hline & WKY-L Apo & 8 & $115 \pm 2$ & $122 \pm 4$ & & $123 \pm 2$ & $\dagger$ \\
\hline & WKY-L Cat & 8 & $122 \pm 4$ & $132 \pm 2$ & & $131 \pm 6$ & $\dagger$ \\
\hline & WKY-L ApoCat & 8 & $118 \pm 4$ & $121 \pm 6$ & & $115 \pm 3$ & $\dagger$ \\
\hline \multirow{5}{*}{$\begin{array}{l}\text { Heart rate } \\
(B P M)\end{array}$} & WKY-C & 8 & $300 \pm 11$ & $301 \pm 12$ & & $298 \pm 21$ & \\
\hline & WKY-L & 8 & $306 \pm 12$ & $283 \pm 3$ & $*$ & $278 \pm 2$ & *,\# \\
\hline & WKY-L Apo & 8 & $298 \pm 12$ & $306 \pm 21$ & & $301 \pm 16$ & $\dagger$ \\
\hline & WKY-L Cat & 8 & $301 \pm 5$ & $314 \pm 9$ & & $316 \pm 6$ & $\dagger$ \\
\hline & WKY-L ApoCat & 8 & $297 \pm 12$ & $294 \pm 11$ & & $296 \pm 19$ & $\dagger$ \\
\hline \multirow{5}{*}{$\begin{array}{l}\text { Urine output } \\
(\mathrm{ml} / \mathrm{kg} / \text { day })\end{array}$} & WKY-C & 8 & $4.05 \pm 0.73$ & $4.34 \pm 0.91$ & & $4.40 \pm 0.87$ & \\
\hline & WKY-L & 8 & $3.91 \pm 0.91$ & $3.19 \pm 0.86$ & $*$ & $3.15 \pm 0.79$ & *\#\# \\
\hline & WKY-L Apo & 8 & $4.07 \pm 0.91$ & $3.95 \pm 0.4$ & & $4.07 \pm 0.73$ & $\dagger$ \\
\hline & WKY-L Cat & 8 & $4.21 \pm 0.61$ & $4.10 \pm 0.81$ & & $4.45 \pm 1.8$ & $\dagger$ \\
\hline & WKY-L ApoCat & 8 & $4.07 \pm 0.86$ & $4.03 \pm 0.69$ & & $4.09 \pm 0.96$ & $\dagger$ \\
\hline \multirow{5}{*}{$\begin{array}{l}\text { Creatinine } \\
\text { clearance } \\
(\mathrm{ml} / \mathrm{min} / \mathrm{kg})\end{array}$} & WKY-C & 8 & $1.65 \pm 0.37$ & $1.62 \pm 0.46$ & & $1.72 \pm 0.56$ & \\
\hline & WKY-L & 8 & $1.69 \pm 0.26$ & $1.29 \pm 0.18$ & $*$ & $0.97 \pm 0.05$ & $*$,\# \\
\hline & WKY-L Apo & 8 & $1.62 \pm 0.27$ & $1.71 \pm 0.16$ & & $2.04 \pm 0.17$ & $*, \mathbb{\# , \dagger}$ \\
\hline & WKY-L Cat & 8 & $1.62 \pm 0.21$ & $1.72 \pm 0.27$ & & $1.91 \pm 0.16$ & $*, \dagger$ \\
\hline & WKY-L ApoCat & 8 & $1.63 \pm 0.25$ & $1.89 \pm 0.28$ & & $2.16 \pm 0.17$ & $*, \#, \oplus$ \\
\hline \multirow{5}{*}{$\begin{array}{l}\text { Fractional } \\
\text { excretion of } \\
\text { sodium (\%) }\end{array}$} & WKY-C & 8 & $0.80 \pm 0.08$ & $0.93 \pm 0.13$ & & $0.88 \pm 0.16$ & \\
\hline & WKY-L & 8 & $0.84 \pm 0.09$ & $0.53 \pm 0.04$ & $*$ & $0.55 \pm 0.09$ & $*, \#$ \\
\hline & WKY-L Apo & 8 & $0.86 \pm 0.10$ & $0.99 \pm 0.13$ & & $0.85 \pm 0.08$ & $\dagger$ \\
\hline & WKY-L Cat & 8 & $0.89 \pm 0.14$ & $0.93 \pm 0.12$ & & $0.94 \pm 0.09$ & $\dagger$ \\
\hline & WKY-L ApoCat & 8 & $0.87 \pm 0.07$ & $1.03 \pm 0.13$ & & $1.06 \pm 0.11$ & $\dagger$ \\
\hline
\end{tabular}

Data presented as mean \pm SEM. $* \mathrm{P}<0.05$ from Day $0 ;{ }^{*} \mathrm{P}<0.05$ of all groups vs. WKY-C except WKY-L (Day 14$) ;{ }^{*} \mathrm{P}<0.05$ of WKY-L vs. WKY-C (Day 14); ${ }^{\dagger} \mathrm{P}<0.05$ of WKY-L Apo, WKY-L Cat and WKY-L ApoCat vs. WKY-L (Day 14); ${ }^{\uparrow} P<0.05$ of WKY-L Cat vs. WKY-L ApoCat (Day 14). 
There was no significant difference in water intake (Table 1) across all experimental groups as the study progressed except that WKY-L animals experienced a significant $(\mathrm{P}<0.05)$ reduction of water intake on day 7 which continued till day 14. Administration of apocynin, catalase and combined apocynin plus catalase in WKY-LApo, WKY-LCat and WKY-LApoCat animals significantly ameliorated $(\mathrm{P}<0.05)$ the water intake compared to the WKY-L group (Table 1).

Effect of apocynin and catalase on systolic blood pressure and heart rate

SBP in WKY-C rats remained stable throughout the study period (Table 1). On the other hand, the SBP of WKY-L rats had significantly $(\mathrm{P}<0.05)$ increased by day 7 and continued to rise until day 14 (Table 1). However, in WKY-LApo, WKY-LCat and WKYLApoCat rats, the SBP was significantly lower as compared to WKY-L rats at the end of day 14 (Table 1).

The heart rate of WKY-C rats was unchanged during the whole experiment period (Table 1). There was a significant $(\mathrm{P}<0.05)$ reduction of heart rate in WKY-L rats which started at day 7 and lasted until day 14 (Table 1). By contrast, heart rates in the WKY-LApo, WKY-LCat and WKY-LApoCat groups of rats (Table 1) were significantly higher compared to the WKY-L (all $\mathrm{P}<0.05)$. However, the heart rate of WKY-LCat rats was still significantly $(\mathrm{P}<0.05)$ higher than WKY-LApoCat rats (Table 1).

Effect of apocynin and catalase on renal functional parameters

No differences were noted in the initial urine output between any of the experimental groups (Table 1). However, there was a significant $(\mathrm{P}<0.05)$ decrease of urine output in WKY-L rats on day 7 and which progressed till day 14. At the end of the day 14 in the WKY-LApo, WKY-LCat and WKY-LApoCat groups of rats there was significantly (all $\mathrm{P}<0.05$ ) improved urine output (Table 1). A similar pattern of response was also observed in $\mathrm{FE}_{\mathrm{Na}}{ }^{+}$(Table 1).

A constant $\mathrm{CrCl}$ was observed in the WKY-C rats throughout the entire study period (Table 1). However, the $\mathrm{CrCl}$ of $\mathrm{WKY}-\mathrm{L}$ rats was significantly $(\mathrm{P}<0.05)$ decreased from day 7 till day 14 (Table 1). At the end of the treatment period, $\mathrm{CrCl}$ in the WKY-LApo, WKY-LCat and WKY-LApoCat groups of rats were significantly (all $\mathrm{P}<0.05$ ) higher compared to their WKY-L counterpart as well as that of the WKY-C rats $(\mathrm{P}<0.05$; Table 1).
The urinary sodium to potassium ratio of WKY-L rats was reduced significantly $(\mathrm{P}<0.05)$ from day 7 towards day 14 but no significant changes were observed in other experimental groups (Table 1). Data from day 14 showed that in the WKY-LApo, WKY-LCat and WKY-LApoCat rats, there was a significantly $(\mathrm{P}<0.05)$ higher urinary sodium to potassium ratio as compared to WKY-L rats (Table 1).

Basal urinary protein excretion (UPE) was similar in all experimental groups from day 0 to day 7 (Table 1). However, in the WKY-L rats UPE had significantly $(\mathrm{P}<0.05)$ increased by day 14 . Over days 7-14 (Table 1), the WKY-LApo, WKY-LCat and WKY-LApoCat groups of rats had unchanged UPE as compared to WKY-L group (all $\mathrm{P}<0.05$ ). A similar pattern of change was also observed in the kidney index parameter at the end of the experimental period (Table 1).

\section{Effect of apocynin and catalase on baseline hemodynamic parameters}

The basal value of RCBP in the WKY-L group of rats was significantly lower $(\mathrm{P}<0.05)$ compared to the WKY-C rats (Table 2). However, in the WKY-LApo, WKY-LCat and WKY-LApoCat groups of rats RCBP was significantly higher compared to the WKY-L group of rats but did not recover to those of the WKY-C rats (all $\mathrm{P}<0.05$; Table 2).

Unlike the other treatment groups, WKY-L rats showed significantly $(\mathrm{P}<0.05)$ higher $\mathrm{PWV}$ values compared to the WKY-C rats (Table 2). WKY-LApo rats had a significantly $(\mathrm{P}<0.05)$ lower $\mathrm{PWV}$ value as compared to WKY-L rats (Table 2). A similar trend was also been noted in the WKY-LCat rats but although the PWV value was still higher than their WKY-LApo counterparts this was not statistically different $(\mathrm{P}>0.05$; Table 2). The PWV value in the WKY-LApoCat group of rats was significantly $(\mathrm{P}<0.05)$ lower as compared to WKY-L rats (Table 2).

The $\beta$-index of WKY-L rats was significantly $(\mathrm{P}<0.05)$ higher than WKY-C rats (Table 2). However, the $\beta$-index of the WKY-LApo, WKY-LCat and WKY-LApoCat groups of rats was significantly $(\mathrm{P}<0.05)$ lower compared to WKY-L rats (Table 2). Although in WKY-LCat rats the $\beta$-index was significantly $(\mathrm{P}<0.05)$ lower than WKY-L rats, it was still significantly $(\mathrm{P}<0.05)$ higher than WKY-C rats (Table 2).

Effect of apocynin and catalase on oxidative stress markers

The plasma MDA level in WKY-L rats was significantly $(\mathrm{P}<0.05)$ higher than the WKY-C rats 
Table 2. Baseline mean arterial blood pressure, renal cortical blood perfusion (RCBP) given in blood perfusion units (bpu), pulse wave velocity (PWV) and B-index (2.2x(PWV) $/ \mathrm{DBP})$ measured at the end of the experiment on Day 14 in control (WKY-C), L-NAME treated (WKY-L), WKY-L treated with apocynin (WKY-LApo), WKY-L treated with catalase (WKY-LCat) and WKY-L treated with apocynin plus catalase (WKY-LApoCat) rats.

\begin{tabular}{|c|c|c|c|c|c|}
\hline \multirow{2}{*}{ Parameter } & \multicolumn{5}{|c|}{ Group (all n=8) } \\
\hline & WKY-C & WKY-L & WKY-L Apo & WKY-L Cat & WKY-L ApoCat \\
\hline $\begin{array}{l}\text { Baseline } M A P \\
(m m \mathrm{Hg})\end{array}$ & $91 \pm 2$ & $94 \pm 6$ & $99 \pm 3$ & $92 \pm 5$ & $97 \pm 4$ \\
\hline$R C B P(b p u)$ & $295 \pm 4$ & $175 \pm 3^{\#}$ & $270 \pm 6^{¥, \dagger}$ & $251 \pm 2^{¥, \dagger}$ & $269 \pm 6^{¥, \dagger}$ \\
\hline$P W V(m / s)$ & $3.72 \pm 0.002$ & $5.68 \pm 0.004^{\#}$ & $3.83 \pm 0.005^{\dagger}$ & $4.20 \pm 0.001^{\dagger}$ & $3.81 \pm 0.004^{\dagger}$ \\
\hline B-index & $0.38 \pm 0.006$ & $0.58 \pm 0.035^{\#}$ & $0.40 \pm 0.022^{\dagger}$ & $0.46 \pm 0.034^{\mathbf{z}, \dagger}$ & $0.42 \pm 0.022^{\dagger}$ \\
\hline
\end{tabular}

Data presented as mean \pm SEM. ${ }^{*} \mathrm{P}<0.05$ of all group vs. WKY-C except WKY-L; ${ }^{\#} \mathrm{P}<0.05$ of WKY-L vs. WKY-C; ${ }^{+} \mathrm{P}<0.05$ of WKY-L Apo, WKY-L Cat and WKY-L ApoCat vs. WKY-L.

(Fig. 1A). In the WKY-LApo and WKY-LCat groups of rats, the plasma MDA levels were significantly $(\mathrm{P}<0.05)$ lower compared to WKY-L rats but in the WKY-LCat group of rats it was still significantly $(\mathrm{P}<0.05)$ higher than WKY-LApo rats (Fig. 1A). A similar pattern of response was manifested in the WKY-LApoCat group of rats $(\mathrm{P}<0.05)$. Nevertheless, at the end of the treatment period, the plasma MDA level from the WKY-LApo and WKY-LCat rats were still significantly (both $\mathrm{P}<0.05$ ) higher than their WKY-C counterpart (Fig. 1A).

The plasma T-SOD level was significantly $(\mathrm{P}<0.05)$ lower in WKY-L rats when compared to WKY-C rats (Fig. 1B). The T-SOD levels of WKY-LApo, WKY-LCat and WKY-ApoCat rats were significantly $(\mathrm{P}<0.05)$ higher than WKY-L rats (Fig. 1B).

The WKY-L rats exhibited a significantly $(\mathrm{P}<0.05)$ lower plasma $\mathrm{NO}$ levels compared to the WKY-C rats (Fig. 1C). Plasma NO levels in the WKY-LApo, WKY-LCat and WKY-LApoCat groups of rats were significantly (all $\mathrm{P}<0.05$ ) higher compared to their WKY-L counterpart and were almost at a level found in the WKY-C rats (Fig. 1C). However, the plasma NO level in WKY-LCat rats was still significantly $(\mathrm{P}<0.05)$ lower than their WKY-C counterpart (Fig. 1C).

The plasma T-AOC in the WKY-L rats was significantly $(\mathrm{P}<0.05)$ lower compared to the WKY-C rats (Fig. 1D). However, in the WKY-LApo, WKY-LCat and WKY-LApoCat groups of rats T-AOC levels were significantly $(\mathrm{P}<0.05)$ higher compared to WKY-L rats (Fig. 1D). Furthermore, their plasma T-AOC levels recovered to values similar to that observed in the WKY-C rats except that the WKY-LCat rats still had a significantly $(\mathrm{P}<0.05)$ lower $\mathrm{T}$-AOC level when compared to WKY-C rats (Fig. 1D).
Effect of apocynin and catalase on the relative quantification of renal Nox $4 \mathrm{mRNA}$ expression

Figure 2 shows that in the WKY-L group of rats there was a 2 fold increase in the expression of renal Nox 4 mRNA (Nox 4/ $\beta$-actin mRNA ratio 2.069) compared to the WKY-C group of rats (Nox $4 / \beta$-actin mRNA ratio 1.000). Renal Nox 4 mRNAs expression was significantly (all $\mathrm{P}<0.05$ ) lower in the WKY-LApo (Nox $4 / \beta$-actin mRNA ratio 0.693), WKY-LCat (Nox $4 / \beta$-actin mRNA ratio 0.716 ) and WKY-LApoCat (Nox $4 / \beta$-actin mRNA ratio 0.477 ) groups of rats compared to their WKY-L counterparts (Fig. 2). In addition, the renal Nox 4 RNA expression of the WKY-LApoCat group of rats was significantly $(\mathrm{P}<0.05)$ less than the WKY-LApo and WKY-LCat groups (Fig. 2).

\section{Histopathology evidence}

The renal tissue of the WKY-C group of rats did not show any ultra-structural changes in either the glomerular or tubular regions (Fig. 3A). By contrast, the renal tissue of the WKY-L rats demonstrated a mild arteriolar congestion with prominent focal chronic inflammation (Fig. 3B). Moreover, a mild protein cast was also noted in the renal interstitium beyond the renal capsular region (Fig. 3B, 3B1). The kidney tissues of WKY-LApo, WKY-LCat and WKY-LApoCat groups of rats had glomerular and tubular structures, blood vessels and parenchyma comparable to the WKY-C group of rats as shown in (Figs 3C, 3D, 3E) respectively.

\section{Discussion}

The present study was designed to explore the antioxidant effectiveness of apocynin and catalase in 


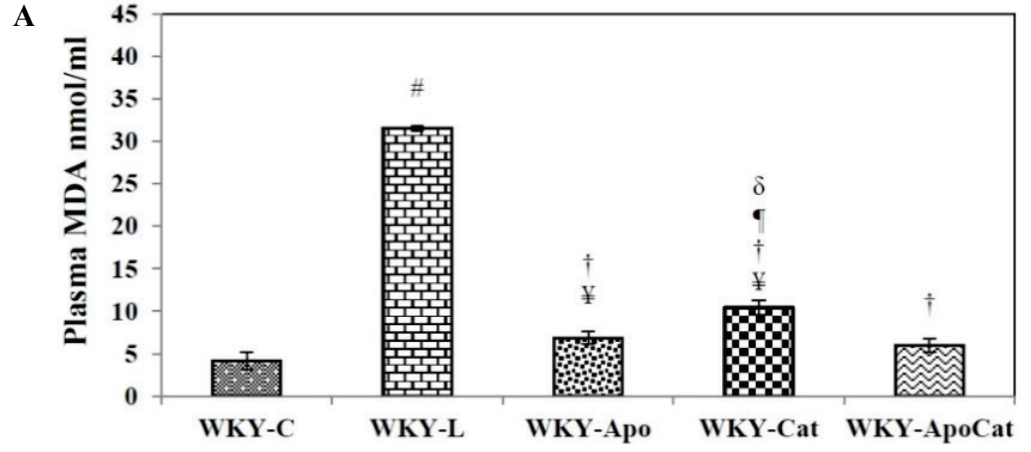

B

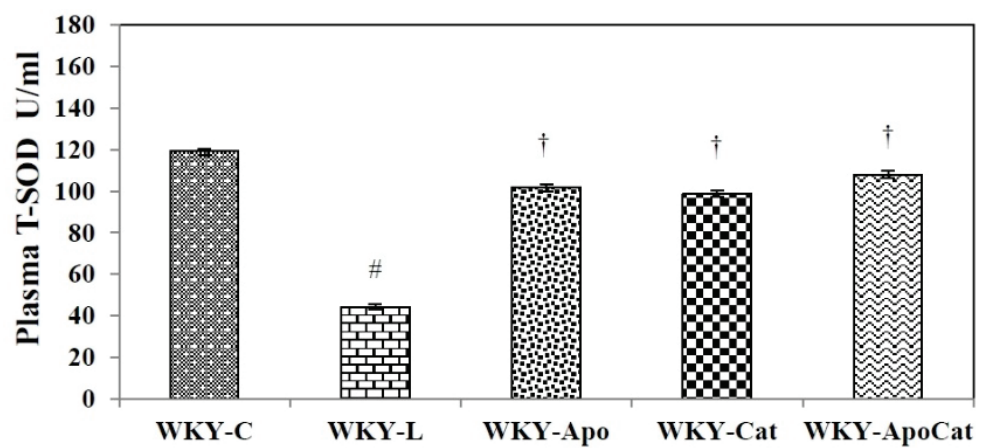

C

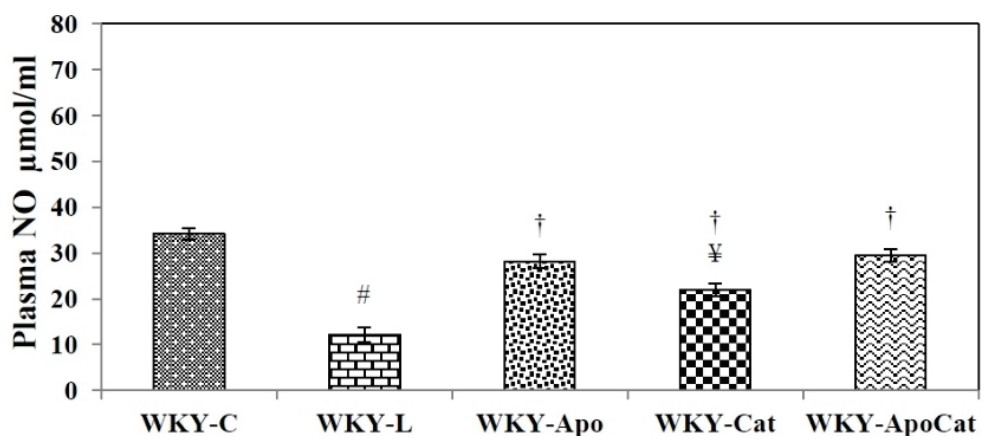

D
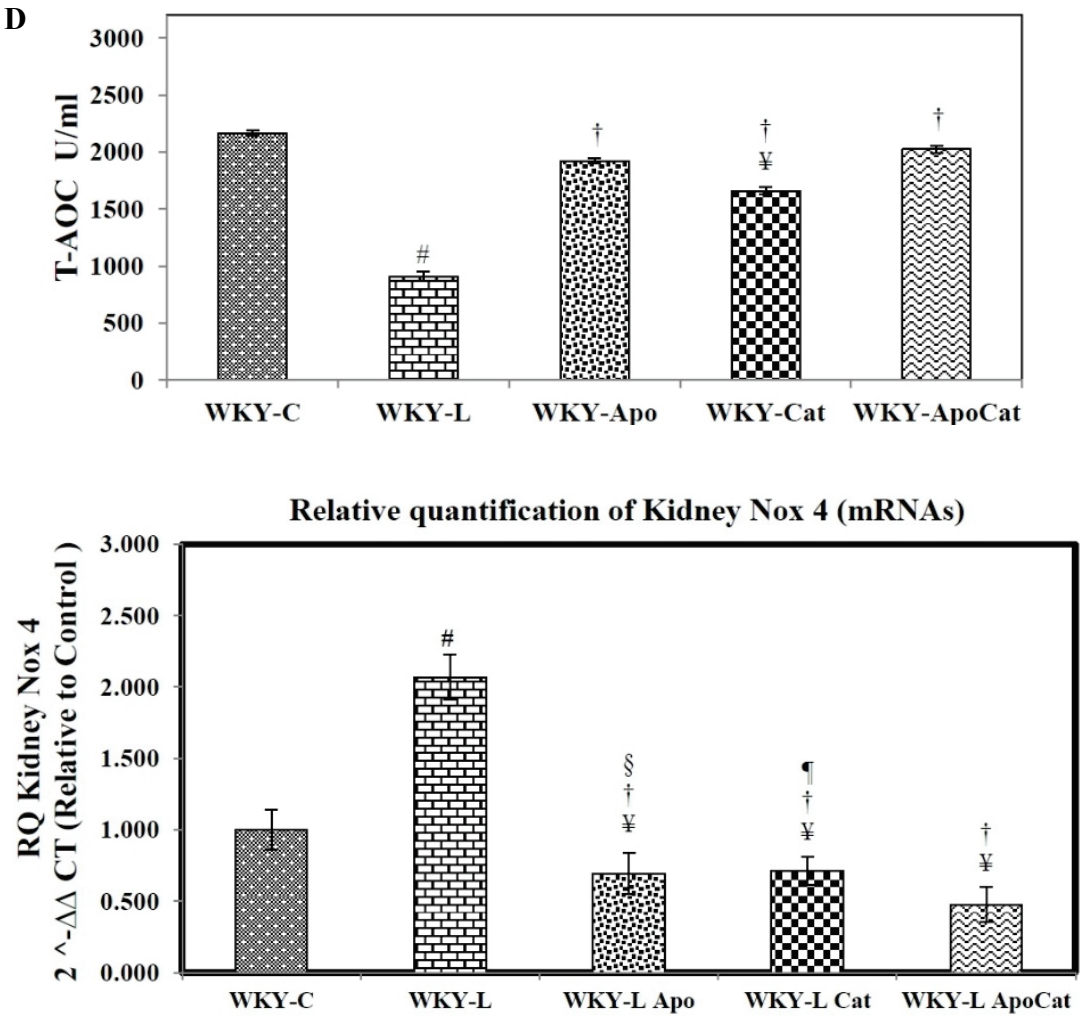

Fig. 1. Biochemical analysis of oxidative stress markers. Plasma levels of MDA (A), T-SOD activity (B), NO (C) and total $\mathrm{AOC}$ (D) were measured in control (WKY-C), L-NAME treated (WKY-L), WKY-L treated with apocynin (WKYLApo), WKY-L treated with catalase (WKY-LCat) and WKY-L treated with apocynin plus catalase (WKY-LApoCat) rats. Values are mean \pm SEM. ${ }^{*} \mathrm{P}<0.05$ of all group vs. WKY-C except WKY-L; ${ }^{\#} \mathrm{P}<0.05$ of WKY-L vs. WKY-C; ${ }^{+} \mathrm{P}<0.05$ of WKY-L Apo, WKY-L Cat and WKY-L ApoCat vs. WKY-L; " $P<0.05$ of WKY-L Cat vs. WKY-L ApoCat; ${ }^{\boldsymbol{\delta}} \mathrm{P}<0.05$ of WKY-L Cat vs. WKY-L Apo.
Fig. 2. The molecular expression of Nox 4 mRNAs, as relative quantification (RQ) in the whole kidney tissue of control (WKY-C), L-NAME treated (WKY-L), WKY-L treated with apocynin (WKYLApo), WKY-L treated with catalase (WKY-LCat) and WKY-L treated with apocynin plus catalase (WKY-LApoCat) rats. Values are mean \pm SEM. ${ }^{¥} \mathrm{P}<0.05$ of all group vs. WKY-C except WKY-L; ${ }^{\#} \mathrm{P}<0.05$ of WKY-L vs. WKY-C; ${ }^{+} \mathrm{P}<0.05$ of WKY-L Apo, WKY-L Cat and WKY-L ApoCat vs. WKY-L; ${ }^{\S} \mathrm{P}<0.05$ of WKY-L Apo vs. WKY-L ApoCat; " $P<0.05$ of WKY-L Cat vs. WKY-L ApoCat. 

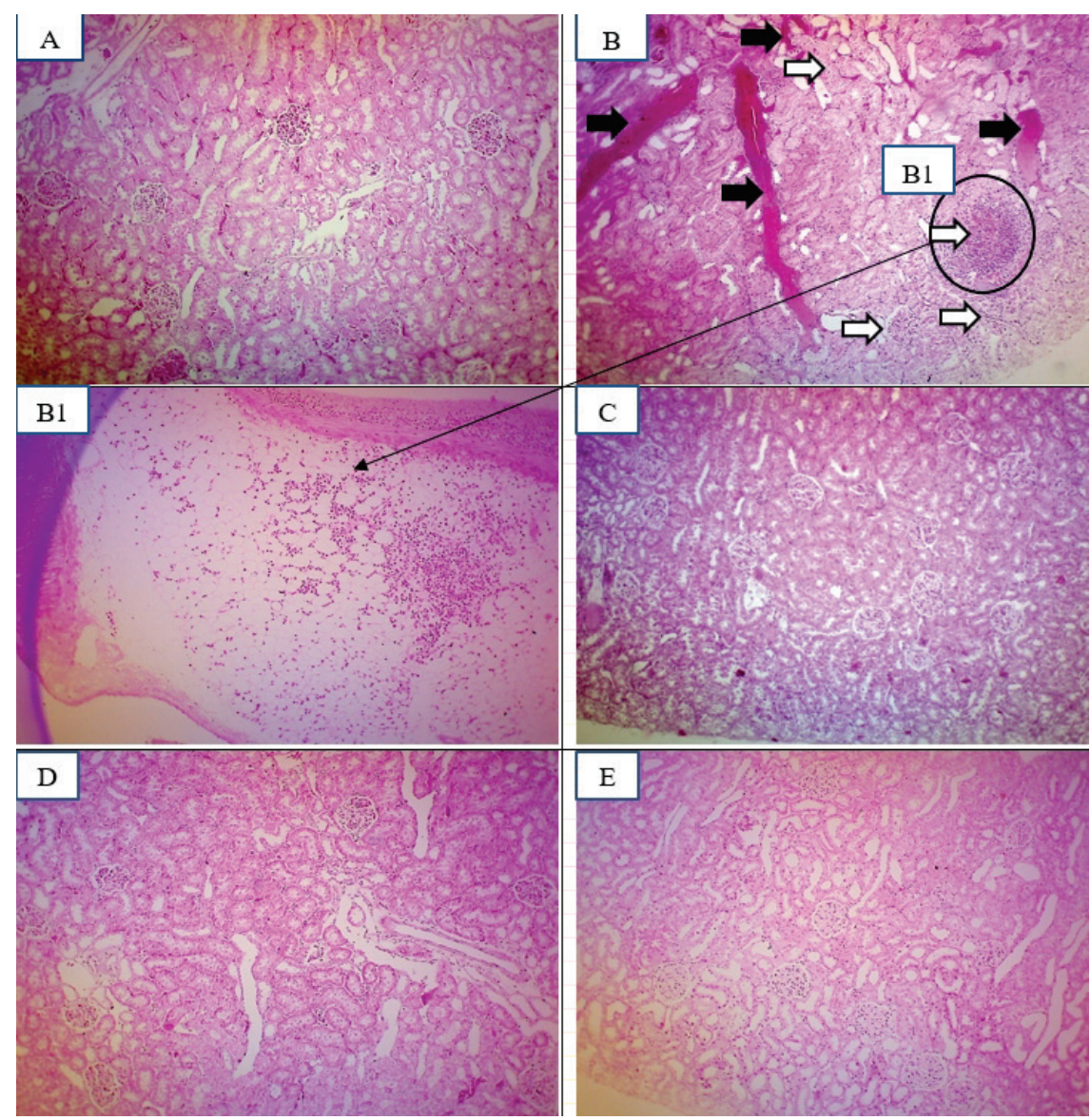

Fig. 3. Histopathological study of rat renal tissue. Renal tissue section from the control (WKY-C)-(A) showed normal glomerular and tubular structures. There was a mild arteriolar congestion (solid arrow) in the kidney of a rat from L-NAME treated (WKY-L)-(B) with prominent focal chronic inflammation and a mild protein cast (open arrow) observed in the renal interstitium near to the capsular region (B1), normal renal tissue architecture was observed in WKY-L treated with apocynin (WKY-LApo)-(C), WKY-L treated with catalase (WKY-LCat)-(D) and WKY-L treated with apocynin plus catalase (WKY-LApoCat)-(E) rats.

(Haematoxylin and eosin stain; original magnification $\times 100$ ) an L-NAME induced hypertension rat model via a pharmacological approach. There were two major novel findings. Firstly, chronic administration of apocynin and catalase via a prophylactic approach was able to ameliorate the renal functional and histological derangements induced by L-NAME. Secondly, that in this L-NAME model of hypertension, NADPH oxidase inhibition using apocynin and $\mathrm{H}_{2} \mathrm{O}_{2}$ scavenging with catalase not only improved the renal hemodynamic parameters but also reduced renal Nox 4 mRNAs expression to control levels.

Treatment with L-NAME caused a significant reduction in body weight gain and water intake by the end of the study period compared to the control and apocynin/catalase treated groups. The exact reason behind these findings is not clear but could be possibly due to the changes in metabolism during the hypertensive state (Saha et al. 1996, Xavier et al. 2000). Indeed, the enhanced oxidative stress attributed to the L-NAME induced NO deficiency, has also been reported in cyclosporine A (Chia et al. 2013) and gentamicin (Ibraheem et al. 2011) induced oxidative stress studies. Similar findings were reported previously in L-NAME induced hypertension following administration of an anti- oxidant regime of the superoxide dismutase mimetic tempol (Chia et al. 2013). The present study has added to this view in that apocynin and catalase administration ameliorated the loss of body weight and reduction in water intake. The exact mechanism as to how this antioxidant drug regime tends to support weight gain in this model remains unclear.

One week administration of a moderate dose of L-NAME was sufficient to provide a partial blockade of NO production as evidenced by the reduction in plasma NO, increase in vascular resistance, the development of hypertension, increased PWV, $\beta$-index and a reduction in heart rate. These observations were consistent with previous reports of impaired baroreflex function with a reflex vagally mediated slowing of heart rate together with a blunted high pressure baroreflex range and gain (Howe et al. 1989). By contrast, other researchers have demonstrated that L-NAME increased heart rate (Berkban et al. 2015) but this might simply be the consequence of the different doses of L-NAME and duration of administration that was used. In the present study, animals received a lower dose of L-NAME of shorter duration whereas others have used doses which were some 2.5 times higher and 3 weeks longer. 
Nonetheless, the antihypertensive action of the apocynin and catalase in our study was consistent with previous reports (Adler et al. 2004, Tanir et al. 2005).

NO blockade induces oxidative stress that leads to renal dysfunction (Mount and Power 2006) and in the present investigation, L-NAME administration for 14 days resulted in decreased $\mathrm{CrCl}$ and urinary fluid excretion. There was a reduction in $\mathrm{FE}_{\mathrm{Na}}{ }^{+}$after 7 days of L-NAME administration which reflected an increase in renal tubular sodium reabsorption which would contribute to a fluid volume expansion and elevation in blood pressure (Kang et al. 2004). A further element of the L-NAME induced renal dysfunction was an increase in albuminuria and an augmentation of the kidney index. Although the progression of renal damage varies widely across different experimental models of hypertension, it is increasingly recognized that elevated $\mathrm{BP}$, per se, plays an important role in the progression of renal disease. Moreover, there are a number of possible causes of L-NAME induced hypertension including a reduction in NO elaboration from the NOS isoforms, increased oxidative stress inactivation of $\mathrm{NO}$ and increased production of vasoconstrictors such as endothelin-1 and thromboxane A2 (Loomis et al. 2005, Ahmad et al. 2018).

This investigation has also suggested an association between SBP and vascular $\mathrm{O}_{2}^{-}$production whereby $\mathrm{O}_{2}^{-}$rapidly reacts with $\mathrm{NO}$ to produce peroxynitrite resulting in impaired NO bioavailability. These findings are supported by the observation that in the L-NAME treated animals NO plasma levels were significantly reduced by 2.8 fold and plasma MDA levels were increased by 6.5 fold. Although oxidative injury may not be the sole etiology, it could possibly amplify the impact of both the elevated blood pressure and the presence of other pro-hypertensive factors. This view is further supported by the findings that there were reductions of some 3 fold in plasma T-SOD and 2.3 fold in T-AOC in the L-NAME treated animals. Furthermore, treatment with apocynin and catalase attenuated the oxidative stress attributed to inhibition of NOS where an elevation towards control values in plasma NO, plasma T-SOD and T-AOC levels was observed along with a diminution in plasma MDA levels. Under these conditions, there was an improvement in $\mathrm{CrCl}$, UPE and $\mathrm{FE}_{\mathrm{Na}}{ }^{+}$towards levels observed in the control rats. These findings suggested that both apocynin and catalase play a major role in scavenging the excess $\mathrm{O}_{2}{ }^{-}$during oxidative stress (Ahmeda and Johns 2012, Castro et al. 2012).
Aldosterone enhances tissue generation of oxygen free radicals and systemic inflammation which may contribute to the impaired endothelial vasorelaxation and associated cardiovascular and renal structural and functional abnormalities (Whaley-Connell et al. 2010). A key factor regulating aldosterone secretion is angiotensin II which also has been reported to increase NADPH-driven $\mathrm{O}_{2}{ }^{-}$production in the vasculature (Griendling et al. 1994, Touyz 2005). The significant reduction in urinary sodium to potassium ratio in the L-NAME treated rats implies an activation of the angiotensin-aldosterone axis. The down-regulation of plasma NO in the L-NAME induced hypertensive rats, which indirectly suggests suppression of NO production at a local level, could be associated with an enhanced renal vascular tone with a component due to an angiotensin II mediated vasoconstriction both of which would contribute to the observed reduction in RCBP observed. This view would be supported by the findings of a mild arteriolar congestion associated with prominent focal chronic inflammation and mild protein cast in the renal tissue of the L-NAME treated rats. A further point is that apocynin would have attenuated the increase in $\mathrm{O}_{2}{ }^{-}$production resulting from the renin-angiotensinaldosterone system, leading to a urinary sodium to potassium ratio close to control values. Moreover, the combination of apocynin and catalase resulted in a comparable amelioration of RCBP and renal arteriolar congestion possibly via the same mechanisms.

A primary source for cardiovascular and renal ROS arises from the activity of NADPH oxidases, of which Nox 4 is important in regulating endothelial function and vascular tone (Briones et al. 2011). Nox 4 is usually co-expressed with other homologues such as Nox 1 and Nox 2, but at significantly higher levels as it is expressed throughout the cardiovascular and renal circulatory systems (Lassegue et al. 2012). In the present study, renal Nox 4 mRNA expression in L-NAME treated rats was increased 2.1 fold which suggested that it was NO deficiency which triggered Nox 4 mRNA expression. This relationship was supported by the observation that concurrent administration of apocynin and catalase in the L-NAME treated rats markedly attenuated the increase in Nox 4 mRNA expression. The mechanism whereby apocynin impacts on NADPH oxidase activity is unclear but may result from interference in the oxidase assembly process (Stefanska and Pawliczak 2008) at the membrane level (Johnson et al. 2002). On the other hand, the antioxidative properties of catalase could be linked to the 
continuous catalyzation of $\mathrm{H}_{2} \mathrm{O}_{2}$ to $\mathrm{H}_{2} \mathrm{O}$ and $\mathrm{O}_{2}$ in order to lower peroxynitrite formation, which also has the potential to impair endothelium-dependent vasodilation (Rubbo et al. 1995).

The present study demonstrated that apocynin and catalase exerts protective effects on the development of hypertension and attenuation of the renal functional and structural disturbances induced by the NOS inhibitorL-NAME. This prophylactic drug regime was associated with control levels of plasma NO and reduction in the oxidative stress status markers such as plasma MDA and elevation of plasma T-SOD and plasma T-AOC levels and, reduction in NADPH oxidase subunit Nox 4 expression. The antioxidative stress effectiveness of using a combination of apocynin plus catalase treatment was better than using either apocynin or catalase alone.
Together these findings point the way to the potential usefulness of these compounds in ameliorating the progression of cardiovascular diseases.

\section{Conflict of Interest}

There is no conflict of interest.

\section{Acknowledgements}

This study was funded by the Research University grant from University Sains Malaysia number 1001/PFARMASI/811347. Tan Yong Chia is a recipient of a research fellowship from the Institute of Postgraduate Studies (IPS) of University Sains Malaysia. The Pantai Premier Pathology Sdn Bhd-please explain is acknowledged for the professional service and advice on histopathology studies.

\section{References}

ACTIVIT SRSN: NG-methyl-L-arginine, an inhibitor of L-arginine-derived nitric oxide synthesis, stimulates renal sympathetic nerve activity in vivo. Circ Res 70: 607-611, 1992. https://doi.org/10.1161/01.RES.70.3.607

ADLER S, HUANG $\mathrm{H}$ : Oxidant stress in kidneys of spontaneously hypertensive rats involves both oxidase overexpression and loss of extracellular superoxide dismutase. Am J Physiol Renal Physiol 287: F907-F913, 2004. https://doi.org/10.1152/ajprenal.00060.2004

AHMAD A, SATTAR MA, AZAM M, KHAN SA, BHATT O, JOHNS EJ: Interaction between nitric oxide and renal alpha1-adrenoreceptors mediated vasoconstriction in rats with left ventricular hypertrophyin Wistar Kyoto rats. PLoS One 13: e0189386, 2018. https://doi.org/10.1371/journal.pone.0189386

AHMAD A, SATTAR MA, RATHORE HA, KHAN SA, ABDULLAH NA, JOHNS EJ: Downregulation of cystathionine y lyase and endothelial nitric oxide synthase and reduced responsiveness of Alpha1A adrenergic receptors in the kidneys of left ventricular hypertrophied Wistar Kyoto rats. Turk J Biol 40: 1129-1139, 2016. https://doi.org/10.3906/biy-1506-78

AHMEDA AF, JOHNS EJ: The regulation of blood perfusion in the renal cortex and medulla by reactive oxygen species and nitric oxide in the anaesthetised rat. Acta Physiol 204: 443-450, 2012. https://doi.org/10.1111/j.1748-1716.2011.02346.x

BERKBAN T, BOONPROM P, BUNBUPHA S, WELBAT J, KUKONGVIRIYAPAN U, KUKONGVIRIYAPAN V, PAKDEECHOTE P, PRACHANEY P: Ellagic acid prevents L-NAME-induced hypertension via restoration of eNOS and p47phox expression in rats. Nutrients 7: 5265-5280, 2015. https://doi.org/10.3390/nu7075222

BRIONES AM, TABET F, CALlERA GE, MONTEZANO AC, YOGI A, HE Y, QUINN MT, SALAICES M, TOUYZ RM: Differential regulation of Nox1, Nox2 and Nox4 in vascular smooth muscle cells from WKY and SHR. Am J Hypertens 5: 137-153, 2011. https://doi.org/10.1016/j.jash.2011.02.001

BRUNINI TMC, DE MOURA RS, MALAGRIS LEN, ROBERTS NB, ELLORY JC, RIBEIRO ACM: Diminished L-arginine bioavailability in hypertension. Clin Sci 107: 391-397, 2004. https://doi.org/10.1042/CS20030412

CASTRO MC, FRANCINI F, SCHINELLA G, CALDIZ CI, ZUBIRAS MG, GAGLIARDINO JJ, MASSA ML: Apocynin administration prevents the changes induced by a fructose-rich diet on rat liver metabolism and the antioxidant system. Clin Sci 123: 681-692, 2012. https://doi.org/10.1042/CS20110665

CHAN SHH, TAI MH, LI CY, CHAN JYH: Reduction in molecular synthesis or enzyme activity of superoxide dismutases and catalase contributes to oxidative stress and neurogenic hypertension in spontaneously hypertensive rats. Free Radic Biol Med 40: 2028-2039, 2006. https://doi.org/10.1016/j.freeradbiomed.2006.01.032

CHIA TY: Modification of renal haemodynamics in cyclosporine a-induced renal failure rats by Tempol. MSc Research report, Universiti Sains Malaysia, 2013. 
CHIA TY, MURUGAIYAH V, SATTAR MA, KHAN K, ABDUL N, AHMAD A, ABDULLA MH, JOHNS EJ, MEI HY, AKHTAR S, AHMAD FU: The restorative effect of apocynin and catalase in L-arginine-induced hypotension on normotensive subjects - the role of oxidative stress. Physiol Res 69: 1051-1066, 2020. https://doi.org/10.33549/physiolres. 934426

CHIA TY, SATTAR MA, ABDULLA MH, RATHORE HA, AHMAD FUD, KAUR G, ABDULLAH NA, JOHNS EJ: The effects of tempol on renal function and hemodynamics in cyclosporine-induced renal insufficiency rats. Ren Fail 35: 978-988, 2013. https://doi.org/10.3109/0886022X.2013.809563

CHIA TY, SATTAR MA, RATHORE HA, ABDULLAH MH, SINGH GKC, AHMAD FUD, IBRAHEEM ZO, LI KJ, PEI YP, JIN OH, ABDULLAH NA: JONHS EJ: Superoxide dismutase mimetic tempol normalized the blood pressure and renal functions in L-NAME induced hypertension rats: The role of oxidative stress. Int J Pharm Sci Rev Res 18: 61-71, 2013.

COSSON E, HERISSE M, LAUDE D, THOMAS F, VALENSI PE, ATTALI JR, SAFAR ME: DABIRE H: Aortic stiffness and pulse pressure amplification in Wistar-Kyoto and spontaneously hypertensive rats. Am J Physiol Heart Circ Physiol 292: H2506-H2512, 2007. https://doi.org/10.1152/ajpheart.00732.2006

GEISZT M, KOPP JB, VARNAI P, LETO TL: Identification of renox, an NAD(P)H oxidase in kidney. Proc Natl Acad Sci U S A 97: 8010-8014, 2000. https://doi.org/10.1073/pnas.130135897

GRIENDLING KK, MINIERI CA, OLLERENSHAW JD, ALEXANDER RW: Angiotensin II stimulates NADH and NADPH oxidase activity in cultured vascular smooth muscle cells. Circ Res 74: 1141-1148, 1994. https://doi.org/10.1161/01.RES.74.6.1141

GUZIK TJ, SADOWSKI J, KAPELAK B, JOPEK A, RUDZINSKI P, PILLAI R, KORBUT R, CHANNON KM: Systemic regulation of vascular $\mathrm{NAD}(\mathrm{P}) \mathrm{H}$ oxidase activity and Nox isoform expression in human arteries and veins. Arterioscler Thromb Vasc Biol 24: 1614-1620, 2004. https://doi.org/10.1161/01.ATV.0000139011.94634.9d

HIRAI T, MUSCH TI, MORGAN DA, KREGEL KC, CLAASSEN DE, PICKAR JG, LEWIS SJ, KENNEY MJ: Differential sympathetic nerve responses to nitric oxide synthase inhibition in anesthetized rats. Am J Physiol Regul Integr Comp Physiol 269: R807-R813, 1995. https://doi.org/10.1152/ajpregu.1995.269.4.R807

HOWE PR, ROGERS PF: HEAD GA: Limited baroreflex control of heart rate in young stroke-prone spontaneously hypertensive rats. J Hypertens 7: 69-75, 1989. https://doi.org/10.1097/00004872-198901000-00011

IBRAHEEM ZO, SATTAR MA, RATHORE HA, ABDULLAH MH, YAM MF: Effect of palm oil leaf extract Eliais guinesis (standardized ethanolic fraction) on progression of experimental nephrotoxicity induced by gentamicin in Sprague Dawley rats. Int J Pharm Sci Res 9: 1-6, 2011.

IGNARRO LJ: Nitric oxide: A unique endogenous signaling molecule in vascular biology (Nobel lecture). Angew Chem Int Ed 38: 1882-1892, 1999. https://doi.org/10.1002/(SICI)1521-3773(19990712)38:13/14<1882::AIDANIE1882>3.0.CO;2-V

JOHNS EJ, O'SHAUGHNESSY B, O'NEILL S, LANE B, HEALY V: Impact of elevated dietary sodium intake on NAD (P) H oxidase and SOD in the cortex and medulla of the rat kidney. Am J Physiol Regul Integr Comp Physiol 299: R234-R240, 2010. https://doi.org/10.1152/ajpregu.00541.2009

JOHNSON DK, SCHILLINGER KJ, KWAIT DM, HUGHES CV, MCNAMARA EJ, ISHMAEL F, O'DONNELL RW, CHANG M-M, HOGG MG, DORDICK JS: Inhibition of NADPH oxidase activation in endothelial cells by ortho-methoxy-substituted catechols. Endothelium 9: 191-203, 2002. https://doi.org/10.1080/10623320213638

KANG DG, SOHN EJ, LEE YM, LEE AS, HAN JH, KIM TY, LEE HS: Effects of bulbus Fritillaria water extract on blood pressure and renal functions in the L-NAME-induced hypertensive rats. J Ethnopharmacol 91: 51-56, 2004. https://doi.org/10.1016/j.jep.2003.11.015

KITIYAKARA C, CHABRASHVILI T, CHEN Y, BLAU J, KARBER A, ASLAM S, WELCH WJ, WILCOX CS: Salt intake, oxidative stress, and renal expression of NADPH oxidase and superoxide dismutase. J Am Soc Nephrol 14: 2775-2782, 2003. https://doi.org/10.1097/01.ASN.0000092145.90389.65

LASSEGUE B, GRIENDLING KK: NADPH oxidases: functions and pathologies in the vasculature. Arterioscler Thromb Vasc Biol 30: 653-661, 2010. https://doi.org/10.1161/ATVBAHA.108.181610

LASSEGUE B, SAN MARTIN A, GRIENDLING KK: Biochemistry, physiology, and pathophysiology of NADPH oxidases in the cardiovascular system. Circ Res 110: 1364-1390, 2012. https://doi.org/10.1161/CIRCRESAHA.111.243972 
LEE D-Y, WAUQUIER F, EID AA, ROMAN LJ, GHOSH-CHOUDHURY G, KHAZIM K, BLOCK K, GORIN Y: Nox4 NADPH oxidase mediates peroxynitrite-dependent uncoupling of endothelial nitric-oxide synthase and fibronectin expression in response to angiotensin II: Role of mitochondria reactive oxygen species. J Biol Chem 288: 28668-28686, 2013. https://doi.org/10.1074/jbc.M113.470971

LIVAK KJ, SCHMITTGEN TD: Analysis of relative gene expression data using real-time quantitative PCR and the 2-^^CT method. Methods 25: 402-408, 2001. https://doi.org/10.1006/meth.2001.1262

LOOMIS ED, SULLIVAN JC, OSMOND DA, POLLOCK DM, POLLOCK JS: Endothelin mediates superoxide production and vasoconstriction through activation of NADPH oxidase and uncoupled nitric-oxide synthase in the rat aorta. J Pharmacol Exp Ther 315: 1058-1064, 2005. https://doi.org/10.1124/jpet.105.091728

MOUNT PF, POWER DA: Nitric oxide in the kidney: functions and regulation of synthesis. Acta Physiol 187: 433-446, 2006. https://doi.org/10.1111/j.1748-1716.2006.01582.x

NAKAZONO K, WATANABE N, MATSUNO K, SASAKI J, SATO T, INOUE M: Does superoxide underlie the pathogenesis of hypertension? Proc Natl Acad Sci USA 88: 10045-10048, 1991. https://doi.org/10.1073/pnas.88.22.10045

NISTALA R, WEI Y, SOWERS JR, WHALEY-CONNELL A: Renin-angiotensin-aldosterone system-mediated redox effects in chronic kidney disease. Transl Res 153: 102-113, 2009. https://doi.org/10.1016/j.trs1.2008.12.008

PECHÁNOVÁ O, DOBEŠOVÁ Z, CEJKA J, KUNEŠ J, ZICHA J: Vasoactive systems in L-NAME hypertension: the role of inducible nitric oxide synthase. J Hypertens 22: 167-173, 2004. https://doi.org/10.1097/00004872200401000-00026

RUBBO H, TARPEY M, FREEMAN BA: Nitric oxide and reactive oxygen species in vascular injury. Biochem Soc Symp 61: 33-45, 1995. https://doi.org/10.1042/bss0610033

SAHA SK, OHINATA H, KUROSHIMA A: Effects of acute and chronic inhibition of nitric oxide synthase on brown adipose tissue thermogenesis. Jpn J Physiol 46: 375-382, 1996. https://doi.org/10.2170/jiphysiol.46.375

SELEMIDIS S, SOBEY CG, WINGLER K, SCHMIDT HHHW, DRUMMOND GR: NADPH oxidases in the vasculature: molecular features, roles in disease and pharmacological inhibition. Pharmacol Ther 120: 254-291, 2008. https://doi.org/10.1016/i.pharmthera.2008.08.005

SHOKOJI T, NISHIYAMA A, FUJISAWA Y, HITOMI H, KIYOMOTO H, TAKAHASHI N, KIMURA S, KOHNO M, ABE Y: Renal sympathetic nerve responses to tempol in spontaneously hypertensive rats. Hypertension 41: 266-273, 2003. https://doi.org/10.1161/01.HYP.0000049621.85474.CF

STEFANSKA J, PAWLICZAK R: Apocynin: Molecular aptitudes. Mediators Inflamm 2008: $106507,2008$. https://doi.org/10.1155/2008/106507

TAN YC, ABDUL SATTAR M, AHMEDA AF, ABDUL KARIM KHAN N, MURUGAIYAH V, AHMAD A, HASSAN Z, KAUR G, ABDULLA MH, JOHNS EJ: Apocynin and catalase prevent hypertension and kidney injury in cyclosporine A-induced nephrotoxicity in rats. PLoS One 15: e0231472, 2020. https://doi.org/10.1371/journal.pone.0231472

TANIR HM, SENER T, INAL M, AKYUZ F, UZUNER K, SIVRI E: Effect of quercetine and glutathione on the level of superoxide dismutase, catalase, malonyldialdehyde, blood pressure and neonatal outcome in a rat model of pre-eclampsia induced by NG-nitro-L-arginine-methyl ester. Eur J Obstet Gynecol Reprod Biol 118: 190-195, 2005. https://doi.org/10.1016/j.ejogrb.2004.04.033

TOGASHI H, SAKUMA I, YOSHIOKA M, KOBAYASHI T, YASUDA H, KITABATAKE A, SAITO H, GROSS SS, LEVI R: A central nervous system action of nitric oxide in blood pressure regulation. J Pharmacol Exp Ther 262: 343-347, 1992.

TOUYZ RM: Reactive oxygen species as mediators of calcium signaling by angiotensin II: implications in vascular physiology and pathophysiology. Antioxid Redox Sign 7: 1302-1314, 2005. https://doi.org/10.1089/ars.2005.7.1302

WANG Y-X, HALKS-MILLER M, VERGONA R, SULLIVAN ME, FITCH R, MALLARI C, MARTIN-MCNULTY B, DA CUNHA V, FREAY A, RUBANYI GM: Increased aortic stiffness assessed by pulse wave velocity in apolipoprotein E-deficient mice. Am J Physiol Heart Circ Physiol 278: H428-H434, 2000. https://doi.org/10.1152/ajpheart.2000.278.2.H428 
WHALEY-CONNELL A, JOHNSON MS, SOWERS JR: Aldosterone: role in the cardiometabolic syndrome and resistant hypertension. Prog Cardiovasc Dis 52: 401-409, 2010. https://doi.org/10.1016/j.pcad.2009.12.004

WILLIAMS HC, GRIENDLING KK: NADPH oxidase inhibitors: new antihypertensive agents? J Cardiovasc Pharmacol 50: 9-16, 2007. https://doi.org/10.1097/FJC.0b013e318063e820

WORLD HEALTH ORGANIZATION 2017: "Causes of death 2008: Data sources and methods," Geneva. [Accessed 9th May, 2019], http://www.who.int/healthinfo/global_burden_disease/cod_2008_sources_methods.pdf.

XAVIER F, MAGALHAES AMF, GONTIJO JAR: Effect of inhibition of nitric oxide synthase on blood pressure and renal sodium handling in renal denervated rats. Braz $J$ Med Biol 33: 347-354, 2000. https://doi.org/10.1590/S0100-879X2000000300014 